\title{
PERSEPSI SISWA MENGENAI MANAJEMEN PENDIDIKAN KARAKTER YANG COCOK UNTUK GENERASI MUSLIM MILENIAL DI KOTA MATARAM
}

\author{
Muhammad Faqih, M.Pd \\ Program Studi Adminstrasi Pendidikan, FIPP UNDIKMA \\ muhammadfaqih444@gmail.com
}

\begin{abstract}
Abstrak: Penelitian ini bertujuan untuk menggali persepsi siswa mengenai pendidikan karakter yang cocok untuk generasi muslim milenial di Kota Mataram. Penelitian ini menggunakan desain penelitian kuanitatif dengan teknik survey. Teknik penentuan sampel menggunakan teknik Slovin. terpilih 25 sekolah tingkat menengah atas. Jumlah responden sebanyak 325 orang yang dipilih secara acak (random sampling). Hasil survey menemukan bahwa (1) sebanyak 95\% siswa menegah atas di Kota Mataram adalah muslim milenialis.(2) ada sembilan karakter siswa muslim milenial; (3) ada tujuh prinsip pendidikan karakter yang cocok untuk siswa muslim milenial; (4)menemukan manajemen pendidikan karkter yang cocok dengan siswa muslim milenial; (5) Budayasekolah yang cocok dengan generasli muslim milenial; (6) Kepemimpinan sekolah yang cocok untuk generasi muslim milenial. Survey merekomendasikan agar (1) ke depan sekolah perlu merancang pendidikan karakter yang sesuai dengan karakter generasi muslim milenial dan prinsip pendidikan karakter muslim milenial. (2) ke depan sekolah perlu merancang budaya sekolah yang sesuai prinsip dan karakter generasi muslim milenial; (3) menyiapkan kepemimpinan sekolah yang cocok dengan karakter dan prinsip pendidikan karakter generasi muslim milenial.
\end{abstract}

\section{Kata Kunci: Persepsi Siswa, Manajemen, Pendidikan Karakter, Generasi Muslim Milenial}

\section{PENDAHULUAN}

Neil Howe dan William Strauss, penulis buku Generations: The History of America's Future. mendefinisikan kohort milenium sebagai terdiri dari individu yang lahir antara 1982 dan 2004. Pedoman Baru Mendefinisikan-ulang Tahun Kelahiran untuk Milenial, Gen-X, dan post Milenium. Generasi Senyap: Lahir 1928-1945 (73-90 tahun). Baby Boomers: Lahir 1946-1964 (5472 tahun). Generasi X: Lahir 1965-1980 (38-
53 tahun). Milenial: Lahir 1981-1996 (22-37 tahun). Gen $\mathrm{Z}$ adalah generasi terbaru yang diberi nama dan dilahirkan antara tahun 1995 dan 2015. Mereka saat ini berusia antara 4-24 tahun (hampir 74 juta di AS).

National Chamber Foundation (NCF), merilis hasil survey mengenai beberapa karakteristik dari generasi milenial. Menurut $\mathrm{NCF}$, generasi milenial adalah generasi yang lahir dari tahun 1980 sampai 1999.

\section{Generasi Hari Ini}

$\begin{array}{lll} & \text { Lahir } & \text { Umur (tahun 2012) } \\ \text { Generasi GI } & 1901-1924 & 88-111 \\ \text { Generasi senyap } & 1925-1946 & 66-87 \\ \text { Generasi Baby Boom } & 1946-1964 & 48-65 \\ \text { Generasi X } & 1965-1979 & 33-47 \\ \text { Generasi Milenial } & 1980-1999 & 13-32 \\ \text { Generasi Z } & 2000- & 12 \text { dan di bawah }\end{array}$

Sifat umum dari generasi milenial di Amerika dipengaruhi oleh beberapa peristiwa sosial antara lain peristiwa WTC 9/11, terorisme, penembakan di sekolah, Tsunami di Asia Tenggara, bdai Katrina, Pemilu 2000, pemakzulan presiden, dan resesi dunia.
Karakteristik umum post milenial antara lain: dipelihara dan dimanjakan oleh orang tua yang tidak ingin membuat kesalahan dari generasi sebelumnya, milenium percaya diri, ambisius, dan berorientasi pada prestasi. Mereka juga 
memiliki harapan yang tinggi terhadap majikan mereka, cenderung mencari tantangan baru di tempat kerja, dan tidak takut mempertanyakan otoritas.

Milenium tumbuh di dunia yang dipenuhi elektronik, online, dan jejaring sosial. Generasi yang paling beragam secara etnis, Millennial cenderung toleran terhadap perbedaan. Setelah dibesarkan dengan mantra "ikuti impianmu" dan diberi tahu bahwa itu istimewa, mereka cenderung percaya diri. Sementara sebagian besar sifat positif, kepercayaan generasi Milenial telah diperdebatkan untuk meluas ke ranah hak dan narsisme. Mereka sering dipandang sebagai sedikit lebih optimis tentang masa depan daripada generasi lain.

Mereka tumbuh dengan perangkat digital yang menggabungkan komunikasi, hiburan, belanja, pemetaan dan pendidikan semuanya dalam satu. Generasi Millenial adalah generasi sosial mereka bersosialisasi sambil mengonsumsi produk dan layanan . Mereka berkolaborasi dan bekerja sama - satu sama lain.

Mereka mencari petualangan (dan apa pun yang terjadi). Ketika milenium makan, misalnya, mereka sering mencari sesuatu yang eksotis, suka bertualang, berkesan atau baru untuk dijelajahi selama pengalaman bersantap mereka. Generasi Millenial adalah generasi yang sangat didorong oleh nilai, khususnya dalam hal nilai-nilai itu penulis Winograd dan Hals menyebut nilai-nilai "sipil"

Karakter lain dari pelajar milenial antara lain: 1) Gairah dengan suatu tujuan. setiap pengalaman eLearning harus memiliki semacam makna, apa pun masalahnya. Anda tidak dapat mengharapkan mereka untuk terlibat dan berpartisipasi jika mereka tidak tahu ke mana mereka akan pergi atau apa yang akan mereka dapatkan dari usaha tersebut'; 2) Multitasking: generasi milenium akan melakukan yang terbaik untuk melakukan berbagai hal secara bersamaan. 3) Tantang otoritas. mereka suka menantang status quo dan berbicara dalam pikiran mereka jika mereka berpikir sesuatu dapat dilakukan dengan lebih baik atau lebih efisien. 4) Guru Teknologi. Milenium dibesarkan dengan teknologi. Mereka menyadari bahwa media sosial dan alat teknologi lainnya adalah aset kuat dalam hampir setiap aspek kehidupan mereka. 5) Dapat beradaptasi. Generasi ini fleksibel. Mereka beradaptasi dengan situasi dengan cukup mudah, berkat kenyataan bahwa mereka mengakui pentingnya perubahan dan pertumbuhan pribadi. 6) Pelajar seumur hidup. Pembelajar milenial adalah pembelajar seumur hidup. Mereka mengerti bahwa meninggalkan sekolah hanyalah awal dari perjalanan pendidikan mereka. 7) Mendambakan pengakuan. Generasi milenium membutuhkan pengakuan, pujian, dan umpan balik secara teratur. Ini bukan karena mereka tidak percaya diri atau kurang percaya diri, tetapi karena mereka perlu tahu bahwa mentor dan penyelia mereka mengakui kerja keras dan upaya mereka. 8) Tidak takut risiko. Sementara generasi sebelumnya mungkin mendambakan stabilitas dan keamanan, generasi milenium lebih memilih untuk mengambil risiko dengan harapan mendapat imbalan.

Bagimana dengan generasi milenial di Indonesia? CSIS (2017) menelusuri orientasi sosial, ekonomi dan politik generasi mileial Indonesia. CSIS menemukan bahwa Secara umum tidak terdapat perbedaan signifikan antara generasi milenial dan non milenial dalam hal aspirasi, harapan, dan persepsi terhadap pemerintahan. Tetapi mereka lebih mempunyai akses dan nyaman terhadap media sosial, mempunyai potensi untuk berbeda dalam banyak hal. Pengaruh generasi milenial dalam aspek politik dan ekonomi belum terlalu kuat, namun informasi di media social semakin dapat dipercaya dan membentuk generasi yang lebih kuat.

Noorhaidi Hasan (2018) secara spesifik menulis buku mengenai literatur Kesilaman Generasi Milenial. Mungkin semacam referensi bagi generasi muslim 
milenial. Menurut Noorhaidi generasi muslim milenial tampaknya akan bergerak kearah Islamisme popular yaitu pergeseran dari orientasi politik mendirikan Negara Islam menuju dialektika Islam dan budaya popular. Berbagai survey mengenai generasi melinial di Indonesia tampaknya belum ada yang meneliti mengenai keberadaan generasi muslim milenial di sekolah terutama di tingkat Sekolah Menengah Atas (SMA). Beberapa survey ditujukan pada pendidikan karakter seperti misalnya Kemenag RI yang melakukan survey Indeks Karakter Peserta Didik (IKPD) dan hasilnya pada Jenjang Pendidikan Menengah tahun 2019 sebesar 70,70.Nilai ini merupakan angka komposit 58 indikator dan 22 aspek/komponen yang dikelompokkan ke dalam dimensi relijiusitas, nasionalisme, kemandirian, gotong royong, dan integritas dari 34 provinsi di Indonesia.Bila dilihat dari skor keseluruhan ini maka IKPD di Indonesia berkategori "tinggi", meski belum berkategori "sangat tinggi.

Realitas generasi milenial telah disadari sebagai generasi yang eksis tetapi penelitian-penelitian mengenai keberadaan generasi milenial di sekolah masih kurang sekali. Survey ini mencoba untuk melacak keberadaan generasi milenial di tingkat sekolah menengah atas dengan tujuan untuk melihat keberadaan mereka sebagai informasi penting merancang pendidikan yang kompatibel dengan karaktersitik mereka.

\section{PEMBAHASAN}

Survey ini dilaksanakan di Kota Mataram dengan mengambil siswa Sekolah Menengah Atas (SMA) sebagai responden. Kegiatan ini dilaksanakan paa tanggal 11-17 November 2019. Populasi siswa SMA di Kota mataram sebanyak 16.072 orang. Penentuan sampel menggunakan teknik SLOVIN, dari 50 sekolah dipilih sebanyak 25 sekolah. Sedangkan teknik samplingnya menggunakan Random sampling. Dari 16.072 orang siswa tersebut dipilih 325 orang sebagai sampel responden. Survey ini menggunakan angket instrumen untuk mengumpulkan data dan 25 orang surveyor.

\section{Temuan-Temuan Survey \\ Identitas Generasi Milenial di Kota Mataram}

Berbagai lembaga survey telah melakukan penelitian mengenai generasi milenial di Indonesia. Survey ini hanya mengambil 4 indikator identitas generasi milenial. Keempat indikator tersebut menjadi indikator untuk melacak keberadaan generasi muslim milenial di Kota Mataram. Generasi muslim milenial diindikasikan dengan keramahan mereka dengan media sosial, mengekspresikan diri melalui media sosial, berorientasi pada enterpreneurship, dan menjadikan kebahagiaan sebagai tujuan hidup. Survey ini menemukan bahwa (1) sebanyak 91,13\% responden mengatakan diri mereka menggunakan media sosial dan 7,7\% tidak menggunakan media sosial. (2) Sebanyak 69,6\% responden membenarkan jika mereka mengekspresikan diri melalui media sosial dan $\mathbf{2 9 , 1 3 \%}$ tidak mengeskpresikan diri di media sosial. Meskipun generasi muslim milenial ini menggunakan media sosial tetapi tidak semuanya mengekspresikan diri di media sosial. (3) sebanyak $\mathbf{7 9 , 8 \%}$ responden membenarkan jika mereka tertarik pada entrepreneurship dan $\mathbf{2 0 . 2 \%}$ tidak tidak tertarik pada dunia usaha atau entrepreneurship. (4) sebanyak $\mathbf{7 9 , 1 1 \%}$ responden membenarkan jika kebahagiaan mereka adalah tujuan terbesar dalam hidup mereka dan $\mathbf{1 9 . 9 \%}$ beranggapan bukan kebahagiaan sebagai tujuan terbesar hidup mereka.

Temuan ini membuktikan bahwa generasi muslim milenial di Kota Mataram ini adalah eksis atau ada. Sebagian besar dari semua siswa di Kota Mataram adalah generasi muslim milenial. Ini artinya sekolah harus mengorientasikan pendidikan pada media sosial, wirausaha, dan kebahagiaan. Begitu juga dengan guru sudah harus menggunakan pembelajaran yang berbasis 
pada media sosial, wirausaha, dan kebahagiaan dalam belajar.

\section{Karakter dan Permasalahan Generasi Muslim Milenial}

Generasi milenial merupakan generasi yang tumbuh dari situasi dan kondisi yang telah berubah terutama ketika revolusi informasi dan teknologi membanjiri dunia. Selain itu abad 21 bukanlah sekedar abad digital yang aman namun secara diam-diam membawa ancaman dan bahaya bagi karakter dan lingkungan generasi muslim milenial. Survey ini menggali persepsi generasi muslim milenial di Kota Mataram mengenai karakter dan permasalahan yang mereka hadapi di lingkungan sekolah.

Survey ini menemukan bahwa (5) sebanyak 95\% responden berpandangan karakter generasi muslilm milenial antara lain religius, kreatif-produktif, reproduktif, berbagi (sharing), Sehat dan baik, taat, target tinggi, solutif-resolutif, problem solver, introspektif, dan mampu keluar dari krisis(out of crisis) dan hanya $\mathbf{5 \%}$ beranggapan ada karakter yang lain. (6) sebanyak 99\% responden mengatakan rokok, minuman keras dan narkotika adalah permasalahan generasi milenial dan 1\% beranggapan ada juga permasalahan lain. (7) sebanyak 96\% responden berpandangan mereka ingin terlibat dalam kampanye melawan rokok, narkotika, dan minuman keras, dan hanya 4\% yang berpandangan lain. (8) sebanyak $\mathbf{9 8 \%}$ responden berpandangan kekerasan masih tinggi (banyak) terjadi di sekolah dan hanya $\mathbf{2 \%}$ yang beranggapan kekerasan tidak terjadi di sekolah. (9) sebanyak 98\% responden berpandangan perilaku bulying masih banyak terjadi di sekolah dan hanya $2 \%$ yang beranggapan tidak terjadi di sekolah.(10) sebanyak $\mathbf{9 8 \%}$ responden ingin terlibat dalam kampanye Anti Bulying dan hanya $2 \%$ yang tidak ingin terlibat dalam kampanye. (11) sebanyak $\mathbf{9 8 \%}$ responden berpandangan perilaku merusak lingkungan sekolah masih tinggi (banyak terjadi) dan hanya $2 \%$ yang berpandangan lain. (12) sebanyak 96\% responden berpandangan mereka ingin terlibat dalam kampanye menghijaukan sekolah dan hanya $4 \%$ yang tidak ingin terlibat dalam kampanye ini. (13) sebanyak $97 \%$ responden berpandangan generasi muslim milenial tidak menyukai isu radikalisme dan penistaan agama dan hanya $3 \%$ yang beranggapan sebaliknya. (14) sebanyak $98 \%$ responden generasi muslim milenial ingin terlibat dalam menghadapi isu radikalisme dan penistaan agama dan hanya 2\% yang tidak ingin terlibat. (15) sebanyak 93\% responden yang berpandangan budaya literasi masih rendah di sekolah dan hanya 7\% yang beranggapan sebaliknya. (16) sebanyak $97 \%$ responden berpandangan sekolah kurang aktif dalam gerakan literasi sosial, alam, quran dan sains quran dan hanya $3 \%$ yang beranggapan justru kegiatan literasi aktif di sekolah.

Temuan ini menunjukkan bahwa karakter generasi muslim milenial di Kota Mataram telah mengalami perubahan kearah yang lebih baik namun pada saat yang sama mereka menghadapi masalah yang bergerak ke arah sebaliknya. Pandangan generasi milenial mengenai perilaku merokok, minuman keras, dan narkotika, kekerasan pada anak, perilaku Bulying, perilaku merusak lingkungan, dan penistaan agama, sama besarnya dengan keinginan mereka untuk menghentikannya. Oleh karena itu sekolah perlu mengawal karakter generasi milenial agar menjadi kekuatan yang positif dan memfasilitasi mereka untuk secara aktif terlibat dalam kegiatan melawan narkoba, global warning, sekolah hijau, anti bulying, dan anti penistaan agama.

\section{Perencanaan Pendidikan Karakter Untuk Generasi Milenial}

Sekolah masih mengorientasikan pembelajaran pada kecerdasan akademik saja. Akibatnya sekolah kurang memperhatikan karakter siswa. Sekolah masih berangapan bahwa lulusan yang baik adalah yang cerdas dan mengabaikan lulusan yang berkarakter. Survey ini menggali persepsi siswa muslim 
milenial mengenai manajemen pendidikan karakter yang cocok dengan siswa muslim milenial.

Survey ini menemukan bahwa (17) sebanyak $98 \%$ responden berpandangan pendidikan karakter bertujuan untuk memperbaiki perilaku dan hanya $2 \%$ yang beranggapan lain. (18) sebanyak 97\% responden berpandangan (a) Netloving /Silaturrahim, (b) Netsharing/Silaturrahman; (c) Komunikasi positif dan saling memuji; (d) Pengusaan dan pengembangan diri; (f) Collective \& Colaborative/Berjamaah; (g) Mengekspresikan Kebenaran dan kebahagiaan; (h) Intelligence\&Awwarness (Mencerdaskan dan Menyadarkan) dan hanya 2\% yang beranggapan bukan prinsip-prinsip pendidikan. (18) sebanyak 97\% responden berpandangan tujuan pendidikan karakter perlu disosialisasikan dan hanya $\mathbf{2 \%}$ yang beranggapan tidak perlu disosialisasikan. (19) sebanyak 96\% responden berpandangan sekolah perlu mengembangkan komponenkomponen pendidikan karakter seperti kurikulum yang milenial, guru yang milenial dan siswa yang milenial dan hanya $\mathbf{4 \%}$ yang beranggapan tidak perlu pengembangan.

Temuan ini menunjukkan bahwa perencanaan pendidikan karakter ke depan perlu mengembangkan prinsip-prinsip pendidikan karakter, mensosialisasikan pendidikan karakter kepada stake holder, dan mengembangkan komponen kurikulum agar lebih milenialis seperti guru yang milenial, metode yang milenial, dan siswa yang milenial. Guru yang milenial tetapi religius, kreatif, produktif, reproduktif, sehat dan baik, taat, prestasi tinggi dan setersunya.

\section{Pengelolaan Pendidikan Karakter Untuk Generasi Milenial}

Persepsi siswa milenial mengenai perencanaan pendidikan karakter menunjukkan pandangan yang maju. Survey ini lebih jauh menggali informasi mengenai persepsi siswa milenial mengenai pengelolaan pendidikan karakter yang cocok untuk generasi muslim milenial. Survey ini menemukan bahwa (20) Sebanyak 91\% responden berpandangan pendidikan karakter yang sesuai dengan generasi milenial perlu diorganisisr dan hanya $\mathbf{9 \%}$ yang beranggapan tidak perlu organisasi. (21) Sebanyak $92 \%$ responden berpandangan kepala sekolah sebagai inisiator dan fasilitator pendidikan karakter untuk generasi milenial dan hanya 9\% yang beranggapan tidak perlu. (22) Sebanyak $\mathbf{9 6 \%}$ responden berpandangan guru perlu memerankan diri sebagai guru yang berkarakter milenial dan hanya $\mathbf{4 \%}$ yang beranggapan tidak perlu memerankan diri. (23) sebanyak 94\% responden berpandangan guru perlu mengelola kelas agar cocok untuk generasi milenial dan hanya $6 \%$ yang beranggapan tidak perlu.

Temuan ini menunjukkan bahwa pengelolaan pendidikan karakter ke depan perlu diorganisir dengan baik, dimana kepala sekolah menjadi inisiator dan fasilitator pelaksanaan pendidikan karakter. Sedangkan guru menjadi modeling pendidikan karakter bagi siswa di luar kelas. Tentu saja siswa milenial akan lebih cepat menerima guru yang juga milenial. Guru juga ke depan perlu memiliki keterampilan mengelola kelas yang sesuai dengan generasi milenial yang kreatif, ramah media sosial dan teknologi.

\section{Pelaksanaan Pendidikan Karakter Untuk Generasi Milenial}

Persepsi siswa milenial dalam hal pelaksanaan pendidikan karkater menunjukkan (24) sebanyak 94\% responden berpandangan guru perlu mengembangkan metode yang sesuai dengan generalisasi milenial dan hanya $6 \%$ yang beranggapan tidak perlu pengembangan. (25) sebanyak 96\% responden berpandangan guru perlu mengembangkan strategi yang sesuai dengan generalisasi meilenial dan hanya $4 \%$ yang beranggapan tidak perlu pengembangan. (26) sebanyak $94 \%$ responden berpandangan perlu program pendidikan karakter yang sesuai dengan generasi milenial dan hanya 6\% yang beranggapan tidak perlu 
pengembangan. (27) sebanyak $\mathbf{9 5 \%}$ responden berpandangan sekolah perlu merancang kegiatan pendidikan karakter dalam bentuk kegiatan harian, mingguan, bulanan, dan tahunan yang sesuai dengan generalisasi milenial dan hanya $5 \%$ yang beranggapan tidak perlu pengembangan. (28) 95\% responden berpandangan sekolah perlu mengintegrasikan pendidikan karakter melelui mata pelajaran dan hanya $5 \%$ yang beranggapan tidak perlu pengintegrasian.

Temuan ini menunjukkan bahwa pelaksanaan pendidikan karakter ke depan perlu mengembangkan metode dan strategi pembelajaran yang cocok dengan generasi milenial dan mengintegrasikannya ke dalam mata pelajaran. Program kegiatan karakter yang berkelanjutan.

\section{Evaluasi Pendidikan Karakter Untuk Generasi Milenial}

Survey ini menemukan bahwa (29) sebanyak $\mathbf{9 5 \%}$ responden berpandangan sekolah menyusun evaluasi pendidikan karakter untuk generasi milenial dan hanya $5 \%$ yang beranggapan tidak perlu menyusun evaluasi. (30) sebanyak $\mathbf{9 4 \%}$ responden berpandangan guru perlu menyusun catatan rekaman penerapan nilai karakter di kelas dan hanya 5\% yang beranggapan tidak perlu menyusun catatan rekaman.

Temuan ini menunjukkan bahwa pendidikan karakter ke depan perlu di evaluasi bukan saja pelaksanaan nilai-nilai itu terlaksana di sekolah tetapi juga di kelas. Tampaknya sudah saatnya evaluasi nilai karakter dilaksanakan di kelas sehingga sekolah memiliki data karakter siswa. Hal ini akan membantu pemerintah pusat dalam melakukan survey karakter.

\section{Budaya Sekolah Untuk Generasi Milenial}

Survey ini menemukan bahwa (31) sebanyak $98 \%$ responden berpandangan guru perlu merancang sembilan budaya sekolah yang milenial dan hanya $2 \%$ yang beranggapan tidak perlu merancang sembilan budaya yang milenial. Temuan ini menunjukkan bahwa budaya religius, budaya kreatif, budaya budaya produktif, budaya reproduktif, budaya sehat, dan baik, budaya taat, budaya prestasi tinggi, budaya budaya resolusi, budaya introspektif, dan budaya mengelola krisis menjadi budaya sekolah yang relevan dengan generasi muslim milenial.

\section{Kepemimpinan Sekolah Untuk Generasi Milenial}

Survey ini menemukan bahwa (32) sebanyak $98 \%$ responden berpandangan perlu kepemimpinan sekolah sesuai dengan generasi milenial adalah kepemimpinan milenial dan hanya $2 \%$ yang beranggapan tidak perlu kepemimpinan milenial. (33) sebanyak $97 \%$ responden berpandangan perlu kepemimpinan milenial yang berorientasi Pada Entrepreneruship, Teknologi, Skill Abad 21, Karakter, dan Literasi Quran dan hanya 2\% yang beranggapan tidak perlu. (34) sebanyak $\mathbf{9 8 \%}$ responden berpandangan kepemimpinan sekolah yang sesuai dengan generasi muslim milenial adalah kepemimpinan yang karakter milenial dan hanya $2 \%$ yang beranggapan tidak perlu. Sebanyak 96\% responden berpandangan kepemimpinan sekolah harus memegang teguh tujuh prinsip-prinsip pendidikan karakter milenial dan hanya $\mathbf{4 \%}$ yang beranggapan tidak perlu.

Temuan ini menunjukkan bahwa kepemimpinan sekolah ke depan tidak lagi sekedar educator, motivator, manajer, tetapi seorang entrepreneur, memiliki kemampuan skill abad 21 namun pada saat yang sama memiliki karakter yang dan prinisp pendidikan karakter yang kuat.

\section{PENUTUP}

Berdasarkan temuan survey di atas maka ada beberapa hal yang perlu kami rekomendasikan yaitu:

1. Perubahan dan perkembangan zaman adalah keniscayaan bahwa generasi milenial adalah eksis dan generasi muslim milenial yaitu siswa milenial di Kota 
Mataram adalah nyata (real). Fakta menuntut sekolah untuk berubah sesuai perkembangan zaman dan kenyataan bahwa siswa yang belajar saat ini adalah siswa milenial.

2. Hal itu berarti bahwa sekolah harus menyesuaikan diri dengan keberadaan mereka dengan segera mengubah diri menjadi sekolah yang adaptif dengan generasi milenial

3. Mengubah manajemen pendidikan karakter saat ini sedang diterapkan di sekolah untuk mengembangkan prinsipprinsip pendidikan karakter yang milenialis, begitu dengan perencanaan, pengelolaan, pelaksanaan, evaluasinya.

4. Mengembangkan sembilan nilai budaya sekolah yang milenialis

5. Kepemimpinan sekolah yang milenialis yaitu kepemimpinan sekolah yang berkarakter dan memegang teguh prinsip pendidikan karakter.

\section{DAFTAR PUSTAKA}

Centre For Strategic and International Studies (CSIS), 2017. Ada Apa Dengan Milenial?
Orientasi Sosial, Ekonomi Dan

Politik. Jakarta:

RilisdanKonferensiPersSurvei CSIS 2017

Noorhaidi

Hasan

LiteraturKeislamanGenerasiMilenialT ransmisi, Apropriasi, Dan Kontestasi. Yogyakarta: UIN SunanKalijaga Press

Strauss, W., \& Howe, N. (1991). Generations: The History of America's Future, 1584 to 2069. New York, NY: William Morrow and Company.

USchamberfoundation.org "National Chamber Foundation (NCF), TheMilenial Generation Research Review".

Wartakota.com. 2020.Survei Tingkat KarakterPesertaDidik di JenjangPendidikanMenengah Level Nasional. 